\title{
Emotions and language - the verbal manifestation of emotions in talk-in- interaction
}

\author{
THOMAS WIBEN JENSEN
}

The aim of this article is to offer a new account of the manifestation and function of emotions in talk-in-interaction. In doing this I combine aspects from two different approaches to emotions - 1) a neuro-scientific approach, and 2) a constructivist and interactional approach - thereby arguing for a more pragmatic and integrated view of emotions in relation to talk-in-interaction. Within the neuroscientific paradigm emotions are viewed as primarily a biological and bodily based phenomenon linked to different areas in the human brain at the expense of the more social and verbal use of emotions. This social focus on the other hand is at the heart of the constructivist approach in which emotions are analyzed as social and verbal actions we perform in our daily interaction, but with no reference to any mental state. The data of my analyses are from recordings of couples therapy. They suggest that descriptions of emotions are often used discursively as a means to produce an understanding of what has just been said whereas the verbal and bodily expressions of emotions are often closely linked to the mental constitution of the emotion itself. In that respect a thorough analysis of emotions in talk-in-interaction must include both the social, mental and even biological dimensions of emotions. 